\title{
XXXIII. “Densities in the earth's crust."
}

\section{Rev. O. Fisher M.A. F.G.S.}

To cite this article: Rev. O. Fisher M.A. F.G.S. (1894) XXXIII. "Densities in the earth's crust.", Philosophical Magazine Series 5, 37:227, 375-379, DOI: 10.1080/14786449408620557

To link to this article: http://dx.doi.org/10.1080/14786449408620557

$$
\text { 曲 Published online: } 08 \text { May } 2009 .
$$

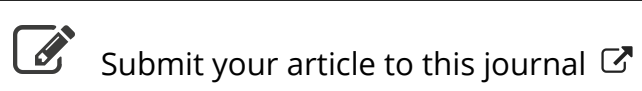

\footnotetext{
Џ Article views: 2
}

Q View related articles $₫$ 
Table VI.-Densities of Solutions of Potassium Hydroxide at $15^{\circ}$.

\begin{tabular}{|c|c|c|c|c|c|}
\hline $\begin{array}{c}\text { Per cent. } \\
\text { KOH. }\end{array}$ & Density. & $\begin{array}{c}\text { Per cent. } \\
\text { KOH. }\end{array}$ & Density. & $\begin{array}{l}\text { Per cent. } \\
\text { KOH. }\end{array}$ & Density. \\
\hline 52 & 1.53822 & 34 & $1 \cdot 33313$ & 16 & $1 \cdot 14925$ \\
\hline 51 & 152622 & 33 & $\begin{array}{l}1 \cdot 32236 \\
\end{array}$ & 15 & $1 \cdot 13955$ \\
\hline 50 & 1.51430 & 32 & 1.31166 & 14 & $\begin{array}{l}1 \cdot 12991\end{array}$ \\
\hline 49 & 1.50245 & 31 & 1.30102 & 13 & $1 \cdot 12031$ \\
\hline 48 & $1 \cdot 49067$ & 30 & l.29046 & 12 & 1.11076 \\
\hline 47 & 1.47896 & 29 & 1.27997 & I1 & $1 \cdot 10127$ \\
\hline 46 & 1.46733 & 28 & 1.26954 & 10 & 1.09183 \\
\hline 45 & 1.45577 & 27 & 1.25918 & 9 & 1.08240 \\
\hline 44 & 1.44429 & 26 & $1 \cdot 24888$ & 8 & 1.07302 \\
\hline 43 & 1.43289 & 25 & $1 \cdot 23866$ & 7 & 1.06371 \\
\hline 42 & 1.42150 & 24 & 1.22849 & 6 & 1.05443 \\
\hline 41 & $1 \cdot 41025$ & 23 & 1.21838 & 5 & 1.04517 \\
\hline 40 & 1.39906 & 22 & 1.20834 & 4 & 1.03593 \\
\hline 39 & $1 \cdot 38793$ & 21 & 1.19837 & 3 & 1.02671 \\
\hline 38 & 137686 & 20 & $1 \cdot 18839$ & 2 & 1.01752 \\
\hline 37 & $1 \cdot 36586$ & 19 & $1 \cdot 17855$ & 1 & 1.00834 \\
\hline 36 & $1 \cdot 35485$ & 18 & $1 \cdot 16875$ & 0 & 0.99918 \\
\hline 35 & 134396 & 17 & $1 \cdot 15898$ & & \\
\hline
\end{tabular}

\section{XXXIII. "Densities in the Earth's Crost." By Rev. O. Fisher, M.A., F.G.S.*}

$\mathrm{N}$ a letter which appears under the above heading in the February number of this Magazine, Mr. Jukes-Browne expresses a wish that I would either admit or deny the value of Professor Blake's criticism $\uparrow$ upon my conclusions concerning the comparative densities and thicknesses of the layers of the earth's crust beneath the oceans and continents respectively.

I do not feel much doubt about the correctness of my work upon this subject, because it was under very careful consideration for several weeks, not only by myself but also by Mr. Brill, whose mathematical ability is unquestionable; and I think Mr. Blake has thrown it aside as unworthy of his consideration rather too hastily. If he had more fully mastered my results, he would not have stated in his first paragraph that "the argument about the underlying layers of the crust seems to depend on the greater density of the superficial layer in continental than in oceanic areas" - which is the exact opposite to the conclusion at which I have

* Comenunicated by the Author.

$\uparrow$ 'Annals of British Geology,' 1892. Introductory review.

$$
202
$$


arrived !* Mr. Blake does not appear to have realized the argument from cap sectors, because he writes of a cap sector beneath the ocean " and another eap sector beneath the land." This was not the idea which I tried to work out.

The subject will be made more intelligible by means of a diagram. The definition of a cap sector was borrowed from: the fifth volume of the 'Account of the Great Trigonometrical Survey of India,' where approximate expressions for the vertical attraction at the apex $A$ of a sector will be found. In my work a cap sector under consideration may be supposed to be partly in the oceanic area and partly in the land; the object being to determine what different arrangements in regard to density and thickness of the

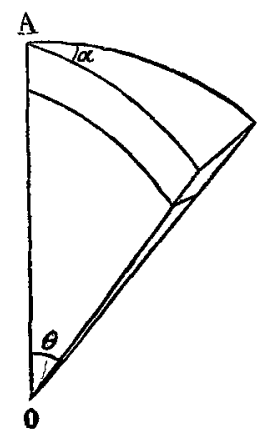
layers in any part of it would have equal effects in contributing to gravity at the point $A$, it being known from M. Faye's investigations $\dagger$ that, when $\mathrm{A}$ is on the ocean, gravity will be the same for all positions of $A$.

The exact expression for the attraction at $A$ for a complete circular cap is given in Pratt's 'Figure of the Earth,' 4th ed. $\S 68$; and to alter it to the case of a sector it is only needful to replace $2 \pi$ by the sector angle $\alpha$.

His expression is of course obtained for the Newtonian law of attraction, and it would be absurd for the case of nature to assume any other $f$. Putting $\alpha$ for the sector angle instead of $2 \pi, \tau$ for the density of the sector, $t$ for its thickness, and $a$ for the radius $\mathrm{OA}$, it can obviously be expanded in a series so that

vertical attraction at $A$

$$
=\alpha\left\{\tau t f^{\prime}(\theta)+\tau \frac{t^{2}}{a} \phi(\theta)+\tau \frac{t^{3}}{a^{2}} \psi(\theta)+\& c_{\odot}\right\},
$$

where $f(\theta), \phi(\theta), \psi(\theta)$, \&c. are (not " unknown" bnt) known functions of $\theta$.

* 'Physics of the Earth's Crust,' 2nd edit., bottom of p. 246. Also Appendix to the same, p. 7.

$\dagger$ Comptes Rendus, March 22, 1886.

f In fact the ocean could not be in equilibrium unless the spherical shells attracted to their common centre, which could only be in the cases of the laws of the direct distance and of the inverse square. 
In fact,

$$
\begin{aligned}
& f(\theta)=1+\sin \frac{\theta}{2}, \\
& \phi(\theta)=-\left(1+\frac{3}{4} \sin \frac{\theta}{2}+\frac{1}{4 \sin \frac{\theta}{2}}\right), \\
& \psi(\theta)=\frac{1}{3}+\frac{1}{8} \sin \frac{\theta}{2}+\frac{5}{24 \sin \frac{\theta}{2}}, \\
& \& c .=\& c .
\end{aligned}
$$

This answers Mr. Blake's objection that "the definite point where the [supposed] fallacy comes in is the assumption that $f(\theta), \phi(\theta), \psi(\theta)$, \&c. are independent.” They are not independent, but are all functions of the same variable.

I will now prove my proposition in a slightly different form from that given in my book, out of regard to Mr. Blake's remark that the method is independent of the law of gravitation.

If we are at liberty to assume any other law than the Newtonian, it will be necessary to introduce a factor $\mathrm{C}$ to make the dimensions right. Then the vertical attraction of a cap sector, of density $\tau$ and thickness $t$, may with this addition be expressed in the above form. Let this be overlapped by another cap sector, of thickness $t_{2}$ and density $\tau_{2}$, or by any number $m$ of cap sectors. Then the vertical attraction of the composite cap sector at $\mathrm{A}$ will be

$$
\mathrm{C} a\left\{\Sigma_{m}(\tau t) f(\theta)+\Sigma_{m}\left(\tau \frac{t^{2}}{a}\right) \phi(\theta)+\Sigma_{m}\left(\tau \frac{t^{3}}{a^{2}}\right) \psi(\theta)+\& \mathrm{c} .\right\} .
$$

Now suppose this composite cap sector to be replaced by another of the same areal dimensions with $n$ layers of thicknesses $t^{\prime}$ \&c. and densities $\tau^{\prime}$ \&c. 'The vertical attraction of this other cap sector at $A$ would be

$$
\mathrm{C}_{\alpha}\left\{\Sigma_{n}\left(\tau^{\prime} t^{\prime}\right) f(\theta)+\Sigma_{n}\left(\tau^{\prime} \frac{t^{\prime 2}}{a}\right) \phi(\theta)+\Sigma\left(\tau^{\prime} \frac{t^{\prime 3}}{a^{2}}\right) \psi(\theta)+\& \mathrm{c} .\right\},
$$

and the difference between the vertical attractions which the two sets of layers would produce would be

$$
\mathrm{C} \alpha\left\{\left(\Sigma_{m}(\tau t)-\Sigma_{n}\left(\tau^{\prime} t^{\prime}\right)\right) f(\theta)+\left(\Sigma_{m}\left(\tau t^{2}\right)-\Sigma_{n}\left(\tau^{\prime} t^{2}\right)\right) \frac{\phi(\theta)}{a}+\& c .\right\},
$$


If the attractions are the same in the two cases for any length whatever of the sector, i.e. for any number of different assumed values of $\theta$, the coefficients of the several functions of the variable must be separately zero. Therefore

$$
\left.\begin{array}{c}
\Sigma_{m}(\tau t)=\Sigma_{n}\left(\tau^{\prime} t^{\prime}\right) \\
\Sigma_{m}\left(\pi t^{2}\right)=\Sigma_{n}\left(\tau^{\prime} t^{\prime 2}\right) \\
\Sigma_{m}\left(\tau t^{3}\right)=\Sigma_{n}\left(\tau^{\prime} t^{\prime 3}\right) \\
\& c .=\& c .
\end{array}\right\} \cdot . \cdot \cdot \cdot
$$

Hence what Mr. Blake says appears to be true, that if the vertical attraction at the apex of a cap sector in the case of any assumed law of attraction can be expanded in the above form, the same proposition regarding the thicknesses and densities will hold good. This will be a remarkable property of the sphere, but it will by no means invalidate any conclusion we can draw from it in the case of the Newtonian law.

Mr. Blake's second objection is that "the same form of equation would result if we had expressed the same supposed arrangement of layers differently, e.g. if we had taken them as non-overlapping, or if we had divided one into two, each of half the thickness." This remark shows that my critic has not appreciated the idea correctly. The quantity $a$ in the expression is the radius to the outside of each layer, and this being the same for them all, they must overlap.

The third objection is, that "it is necessary to assume the equality of the two sides to the same degree of approximation as there are layers in the crust." "Not at all! I have deduced from the equality that two equal and similar areas (or "patches") of any form, of which the layers, whether the same in number or not, and densities are so related, will produce the same gravitational effect at any place, one as the other. Now since gravity is known to be the same all over the ocean, we must have the gravitational effect of an area of flat land the same as that of an oceanic area of the same size and form, and consequently the layers in these two areas must be related, as shown by the equations (A), no hypothesis as to equality in the numbers of layers being made. For example, let there be an area of land at $P$, and a similar one of ocean at 2. Take a point $R$ in the ocean equidistant from $P$ and $Q$; then, remembering that the layers are understood to be underlaid by a centrobaric nucleus, the contribution of $\mathrm{P}$ 
to gravity at $\mathrm{R}$ must be equal to that of $\mathrm{Q}$ to gravity at $\mathrm{R}$ : otherwise gravity at $\mathrm{R}$ would not have its normal value. Hence the layers in the area $\mathrm{P}$ must be related to those in $\mathrm{Q}$ in the manner proved. But it is not by any means necessary that the number $m$ at $\mathrm{P}$ should be the same as the number $n$ at $Q$; and in the particular case which $I$ have shown to be admissible at p. 244, there are at $\mathrm{P}$ on the land side two layers, viz. the crust and the substratum, and at $Q$ in the ocean four, namely, the water, two in the crust, and the substratum.

Mr. Blake further objects that the equations may be indeterminate. If they are so, it does not follow that no conclusions can be drawn from them, because some of the unknown quantities may lie within known limits, which will give limiting values for the others; and this is the method which I have followed. But for the full understanding of the subject reference must be made to chapter xvij. of my book and to chapter xxvi. (Appendix).

Seeing that a further investigation of my equations, suggested by a letter from Mr. Jukes-Browne in 'Nature '*, led me to modify the conclusions given in chap. xvii., I think it will be as well to state the results here, lest any of your readers, not having seen the Appendix, should take the results as stated in chap. xvii. as final:-

"(1) The suboceanic crust dips less deeply into the substratum than does the continental crust at the seaboard.

" (2) The suboceanic crust is less dense in the lower than in the upper portion.

" (3) The lower portion of that crust is also less dense than the substratum beneath it.

"(4) The upper layer of the suboceanic crust is of high density, and quite thin when compared with the whole thickness.

"(5) The substratum beneath the ocean is less dense than beneath the seaboard.

"(6) The continental crust at the seaboard is of uniform density throughout, or, if it does consist of two layers of different density, one of them must be too thin to sensibly affect the gravitational phenomena."

$$
\text { * 'Nature,' vol, xli. p. } 54 \text { (1889). }
$$

